\title{
Long-Term Results and Current Problems in Laparoscopic Gastrectomy: Single-Center Experience
}

\author{
Cemil Yüksel, MD, ${ }^{1}$ Ogün Erşen, MD, ${ }^{1}$ Ümit Mercan, MD, ${ }^{1}$ Salim Illksen Başçeken, MD, \\ Batuhan Bakırarar, PhD, ${ }^{3}$ Sancar Bayar, MD, Ali Ekrem Ünal, MD, and Salim Demirci, MD ${ }^{1}$
}

\begin{abstract}
Introduction: The study aims to evaluate the long-term results of patients who underwent laparoscopic gastrectomy for gastric cancer in Ankara University Medical Faculty, Surgical Oncology Clinic, within 5 years. Materials and Methods: We retrospectively reviewed the data of patients who underwent laparoscopic gastrectomy for gastric cancer at the Surgical Oncology Clinic of Ankara University Medical Faculty between January 2014 and September 2019. One hundred forty-six patients were included in the study.

Results: Fifty-one (34.9\%) of the patients were female; $95(65.1 \%)$ were male. The mean \pm standard deviation and median (minimum-maximum) values of the patients were 60.92 \pm 14.13 and 64.00 (22.00-93.00), respectively (Table 1). Eighty-seven (59.6\%) cases were located in the antrum, 29 (19.9\%) were in the cardia region, and $30(20.5 \%)$ were in the corpus region. Overall, $106(72.6 \%)$ of 146 patients were alive, while 40 (27.4\%) were ex. The mean survival was 21.8 months (0-69). Postoperative mortality was seen in 9 patients $(6.2 \%)$ and our disease-free survival rate was $70.5 \%$. Recurrence occurred in $14(9.6 \%)$ of all patients.

Conclusion: In conclusion, although laparoscopic gastrectomy is a reliable and feasible method for gastric cancer, the standardization of laparoscopic surgery is required in clinics.
\end{abstract}

Keywords: gastrectomy, laparoscopy, oncology, survival

\section{Introduction}

G ASTRIC CANCER IS one of the most common malignancies in the world, and ${ }^{1}$ gastrectomy and proper lymph node dissection have been known to improve survival in gastric cancer for many years. The popularity of laparoscopic gastrectomy is increasing. The first laparoscopicassisted subtotal gastrectomy in history was performed in $1994^{2}$ and the use of laparoscopy has increased over the years as technology advances. Laparoscopic gastrectomy has become a common cause of less postoperative pain, shorter hospital stays, early return of bowel functions, as well as oncologic outcomes similar to open surgery. ${ }^{3,4}$ Laparoscopic gastrectomy is a difficult surgical procedure and various techniques and different studies are available. In a study by Chen et al., laparoscopic gastrectomy was shown to have advantages over open surgery ${ }^{5}$; Lee et al. reported that there were more anastomosis leakage and higher mortality in laparoscopic surgery. ${ }^{6}$ The safety and efficacy of laparoscopic subtotal gastrectomy (LASG) have been proved in worldwide studies, ${ }^{7}$ whereas the safety and efficacy of laparoscopic total gastrectomy (LATG) have not been proved compared to open surgery. The preferred reason for LATG is that in particular, the reconstruction stage includes some technical limitations in conventional surgery. ${ }^{8}$ The study aims to evaluate the long-term results of patients who underwent laparoscopic gastrectomy for gastric cancer in Surgical Oncology Clinic, Ankara University Medical Faculty within 5 years.

\footnotetext{
${ }^{1}$ General Surgery Department, Surgical Oncology Clinic, Ankara University Medicine Faculty, Ankara, Turkey.

${ }^{2}$ Surgical Oncology Clinic, Diyarbakır Research Hospital, Diyarbakir, Turkey.

${ }^{3}$ Biostatistic Department, Ankara University Medicine Faculty, Ankara, Turkey.

(C) Cemil Yüksel et al. 2020; Published by Mary Ann Liebert, Inc. This Open Access article is distributed under the terms of the Creative Commons License (http://creativecommons.org/licenses/by/4.0), which permits unrestricted use, distribution, and reproduction in any medium, provided the original work is properly cited.
} 
Table 1. Patient Characteristics

\begin{tabular}{|c|c|}
\hline Variables & \\
\hline $\begin{array}{l}\text { Age } \\
\text { Mean } \pm \text { SD } \\
\quad \text { Median (min.-max.) }\end{array}$ & $\begin{array}{c}60.92 \pm 14.13 \\
64.00(22.00-93.00)\end{array}$ \\
\hline $\begin{array}{l}\text { Albumin } \\
\text { Mean } \pm \text { SD } \\
\text { Median (min.-max.) }\end{array}$ & $\begin{array}{c}3.90 \pm 0.51 \\
4.00(2.50-5.01)\end{array}$ \\
\hline $\begin{array}{l}\text { Met lymph count } \\
\text { Mean } \pm \text { SD } \\
\text { Median (min.-max.) }\end{array}$ & $\begin{array}{c}8.41 \pm 7.05 \\
6.00(1.00-40.00)\end{array}$ \\
\hline $\begin{array}{l}\text { Total lymph count } \\
\text { Mean } \pm \text { SD } \\
\text { Median (min.-max.) }\end{array}$ & $\begin{array}{c}23.09 \pm 8.97 \\
22.00(4.00-52.00)\end{array}$ \\
\hline $\begin{array}{l}\text { Survival } \\
\text { Mean } \pm \text { SD } \\
\quad \text { Median (min.-max.) }\end{array}$ & $\begin{array}{c}21.83 \pm 17.40 \\
17.50(0.10-69.00)\end{array}$ \\
\hline $\begin{array}{l}\text { Gender, } n(\%) \\
\quad \text { Man } \\
\text { Woman }\end{array}$ & $\begin{array}{l}95(65.1) \\
51(34.9)\end{array}$ \\
\hline $\begin{array}{l}\text { Morbidity, } n(\%) \\
\text { No } \\
\text { Yes }\end{array}$ & $\begin{array}{r}117(80.1) \\
29(19.9)\end{array}$ \\
\hline $\begin{array}{l}\text { TM location, } n(\%) \\
\text { Antrum } \\
\text { Cardia } \\
\text { Corpus }\end{array}$ & $\begin{array}{l}87(59.6) \\
39(19.9) \\
30(20.5)\end{array}$ \\
\hline $\begin{array}{l}\text { Operation, } n(\%) \\
\text { Subtotal } \\
\text { Total }\end{array}$ & $\begin{array}{r}103(70.5) \\
43(29.5)\end{array}$ \\
\hline $\begin{array}{l}\text { Anastomosis, } n(\%) \\
\text { Open } \\
\text { Intracorporeal } \\
\text { Mini-laparotomy }\end{array}$ & $\begin{array}{c}6(4.1) \\
54(37.0) \\
86(58.9)\end{array}$ \\
\hline $\begin{array}{l}\text { Sur comp, } n(\%) \\
\text { No } \\
\text { Yes }\end{array}$ & $\begin{array}{r}131(89.7) \\
15(10.3)\end{array}$ \\
\hline $\begin{array}{c}\mathrm{T}, n(\%) \\
1 \\
2 \\
3 \\
4\end{array}$ & $\begin{array}{l}32(21.9) \\
18(12.3) \\
55(37.7) \\
41(28.1)\end{array}$ \\
\hline $\begin{array}{l}\mathrm{N}, n(\%) \\
\text { Negative } \\
\text { Positive }\end{array}$ & $\begin{array}{l}68(46.6) \\
78(53.4)\end{array}$ \\
\hline $\begin{array}{l}\text { Mortality, } n(\%) \\
\text { No } \\
\text { Yes }\end{array}$ & $\begin{array}{r}106(72.6) \\
40(27.4)\end{array}$ \\
\hline $\begin{array}{l}\text { Recurrence, } n(\%) \\
\text { No } \\
\text { Yes }\end{array}$ & $\begin{aligned} 132 & (90.4) \\
14 & (9.6)\end{aligned}$ \\
\hline
\end{tabular}

$\mathrm{SD}$, standard deviation; TM, tumor.

\section{Materials and Methods}

\section{Selection of patients}

We retrospectively reviewed the data of patients who underwent laparoscopic gastrectomy for gastric cancer at the Surgical Oncology Clinic of Ankara University Medical Faculty between January 2014 and September 2019. Patients younger than 18 years of age, stage 4 , underwent additional visceral organ resection (liver, pancreas, colon, and small intestine), operated for malignant stromal and neuroendocrine tumors, operated under emergency conditions and previously operated for another malignancy were excluded from the study. One hundred forty-six patients were included in the study.

\section{Data collection}

Diagnostic laparoscopy was performed in 68 patients whose operability could not be clarified with preoperative evaluations. Surgical and pathological reports, preoperative hematological and biochemical parameters, tumor markers, demographic characteristics, postoperative complications, postoperative mortality, and total disease-free survival were evaluated. Radiological examinations (chest radiography, computed tomography, ultrasonography, endoultrasonography, magnetic resonance, and positron emission tomography) were examined by scanning retrospectively the electronic files. For staging, the eighth edition of the TNM classification for International Cancer Control ${ }^{9}$ and the Japanese Gastric Cancer Association guidelines ${ }^{10}$ were used. One-seven lymph node stations in D1 dissection and lymph nodes in D1 +8a, 9, 10, 11p, 11d, and 12a stations in $\mathrm{D} 2$ dissection were included. Complications were defined according to the Clavien-Dindo classification. Postoperative complications were accepted as complications that occurred within 90 days and postoperative mortality was accepted as patients who died within 30 days or during hospitalization.

\section{Surgical procedure}

The same surgical team performed all cases. Preoperative informed consent was obtained from the patients for the operation. Intestinal cleaning was performed using laxatives and enemas 1 day before the operation and the patient was operated after 8-hour fasting. Preoperative single-dose prophylactic antibiotic (cefazolin $1 \mathrm{~g}$ ) was administered. Intraoperative normothermia was provided by anesthesiologists and all surgical procedures were performed according to routine asepsis and antisepsis rules. All patients were placed in the opposite Trendelenburg and French positions by closing both arms (Fig. 1). The position was changed according to the stages of the surgery, but the position was mainly on the right side. We entered via a $12 \mathrm{~mm}$ camera trocar (PT00015248; Medtronic, Dublin, Ireland) directly over the umbilicus. Pneumoperitoneum was maintained with a mean of $12-15 \mathrm{mmHg}$. After the pneumoperitoneum was created, a $5 \mathrm{~mm}$ trocar for the left hand of the surgeon, $2 \mathrm{~cm}$ above and $5 \mathrm{~cm}$ left lateral of the camera port, $12 \mathrm{~mm}$ trocar for the right hand, $2 \mathrm{~cm}$ above the camera port, and $5 \mathrm{~cm}$ right lateral were entered into the abdominal cavity. For the assistant, a $5 \mathrm{~mm}$ trocar was entered from the lateral axis of the right $12 \mathrm{~mm}$ trocar through the intersection of the middle axillary line, and finally, an automatic liver retractor (G03123; Cook-Medical, Bloomington) was placed in the subxiphoid region (Fig. 2). A $30^{\circ}$ camera and a laparoscopy system capable of displaying two- or three-dimensional images were used in all cases (OTV-S300; Olympus, Norfolk). After positioning the patient and entering the trocars, exploration was performed and the presence of distant metastasis or peritoneal spread was examined carefully. Then, the 


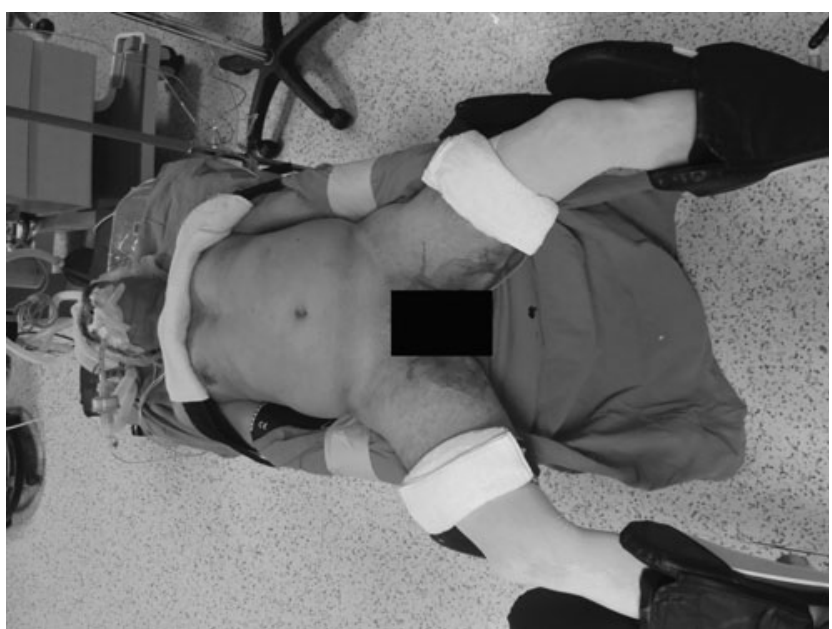

FIG. 1. Patient position.

gastrocolic ligament was opened with ultrasonic scissors (laparoscopic coagulating shears; Ethicon Endo-Surgery, Cincinnati, $\mathrm{OH}$ ) and proceeded until the spleen was seen on the left, and the left gastroepiploic artery was ligated at the root of the vein. Number 4 lymph nodes were included in the specimen (Fig. 3). If total gastrectomy is performed, it is reached to the left crus. On the right side, we proceeded till the duodenum and gall bladder. Above the duodenum, fat was released from the tissues, and the right gastroepiploic artery and vein were ligated and cut with hem-o-loc clips (Weck Closure System; Teleflex Medical, Research Triangle Park, NC) and the infrapyloric lymph nodes (number 6) were included in the specimen (Fig. 4). Then the duodenum was transected with a $45 \mathrm{~mm}$ endoscopic stapler instrument

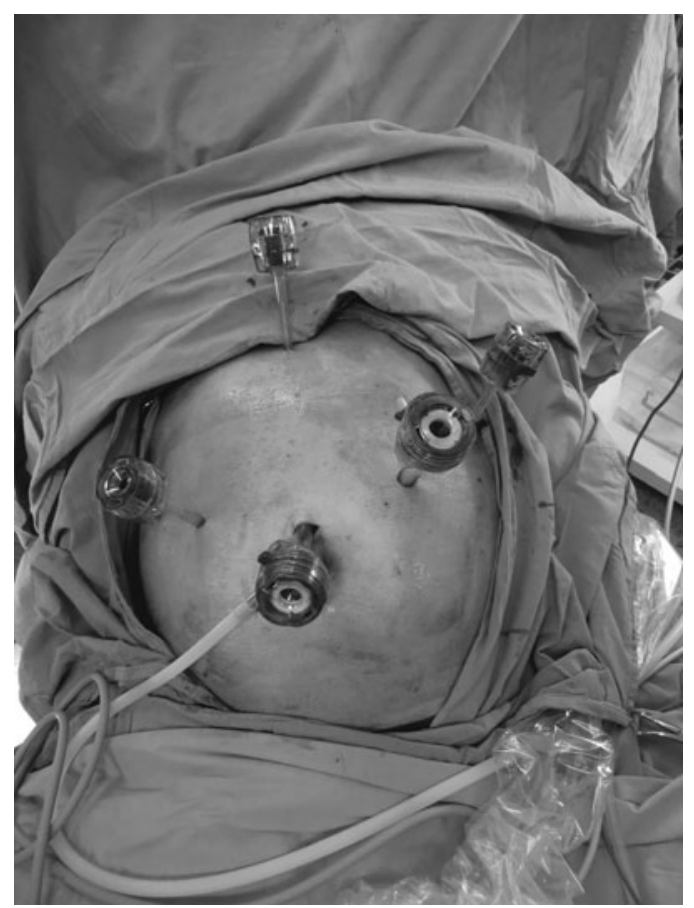

FIG. 2. Port entry places.

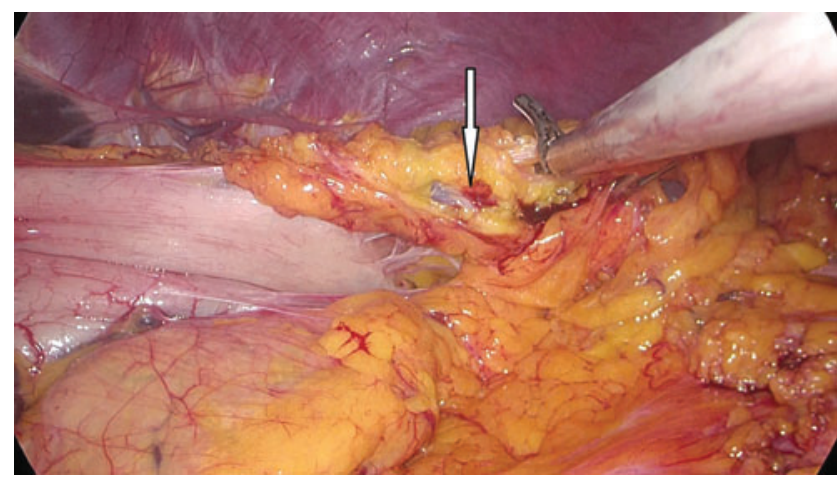

FIG. 3. Left gastroepiploic artery (arrow).

(030459; Medtronic) $2 \mathrm{~cm}$ below the pylor. Then (Fig. 5), the right gastric artery was ligated and cut on the hepatic artery (Fig. 6). The hepatoduodenal ligament was first removed from the posterolateral peritoneum on the portal vein (12p) and the lymph glands were collected, then the pancreas capsule was included and the hepatic artery (number 8a) was cleaned and ligated with the clips of the left gastric artery and vein (number 7). The lymph nodes on the proximal splenic artery were dissected (number 11p) starting from the celiac trunk (Fig. 7) and lymph nodes on the distal splenic artery were included in the specimen (number 11d). From here, we reached the spleen and collected lymph nodes on the vascular structures (number 10). The next step was to include lymph nodes around the small curvature (number 3 ) and dissection of the lymph nodes in the right paracardiac region was completed (Fig. 8).

All patients underwent Roux-en-Y gastrojejunostomy or esophagojejunostomy for reconstruction. From the Treitz, the jejunum was transected from the $20 \mathrm{~cm}$ and the distal part was anastomosed to the stomach or esophagus, while the Y leg was anastomosed to the $40 \mathrm{~cm}$. Some of these anastomoses were performed intracorporeally and some were performed by mini-laparotomy. Mini-laparotomy was performed with a

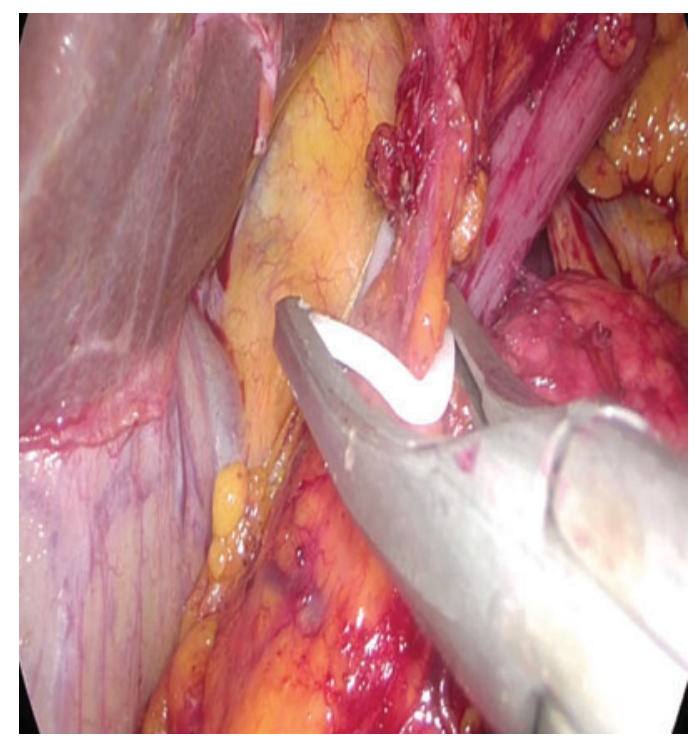

FIG. 4. Clipping of right gastroepiploic artery and vein. 


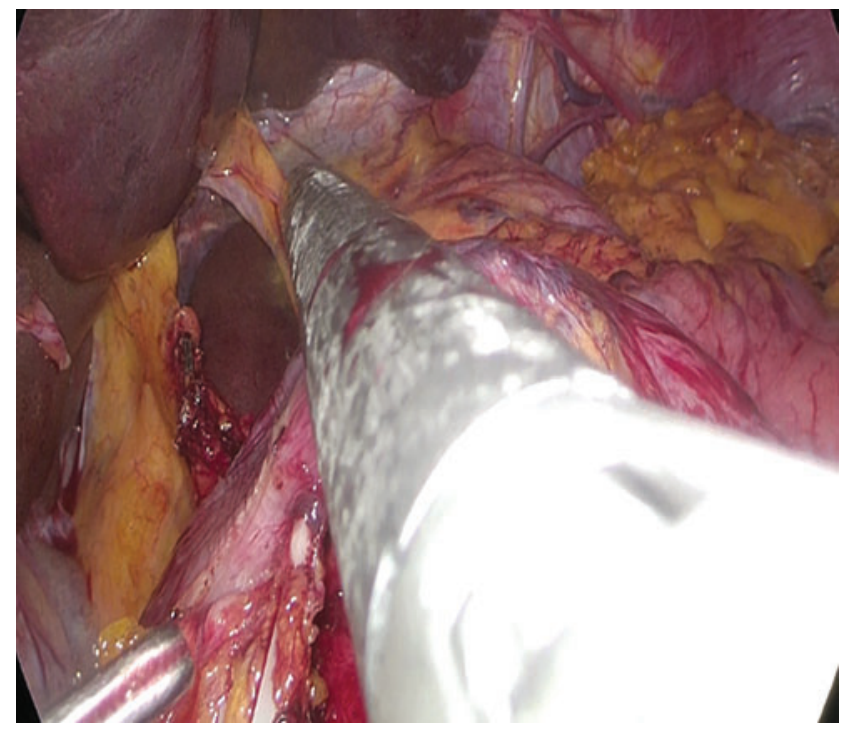

FIG. 5. Cutting the duodenum.

$5 \mathrm{~cm}$ incision in the midline just below the xiphoid. The incision template (Alexis Wound retractor; Applied Medical, Rancho Santa Margarita, CA) was used to minimize skin contact with the incision site. Intracorporeal esophagojejunostomy was performed with a linear stapler and overlap anastomosis. After that, the stapler inlet openings were sutured in double layers (Fig. 9).

The circular stapler was used when mini-laparotomy was performed in the anastomosis. Intracorporeal gastrojejunostomy anastomosis was performed side-by-side with a linear stapler or double-sided, end-to-side by hand. In patients who underwent mini-laparotomy, anastomoses were performed by stapler or by hand. Two drains were placed in the patient who underwent total gastrectomy and one drain was placed in the patient who underwent subtotal gastrectomy.

\section{Statistical analysis}

SPSS for Windows 11.5 program was used for data analysis. The mean \pm standard deviation and median (minimummaximum) were used for the quantitative variables and the number of patients (percentage) for the qualitative variables. Logistic regression analysis was used to evaluate the

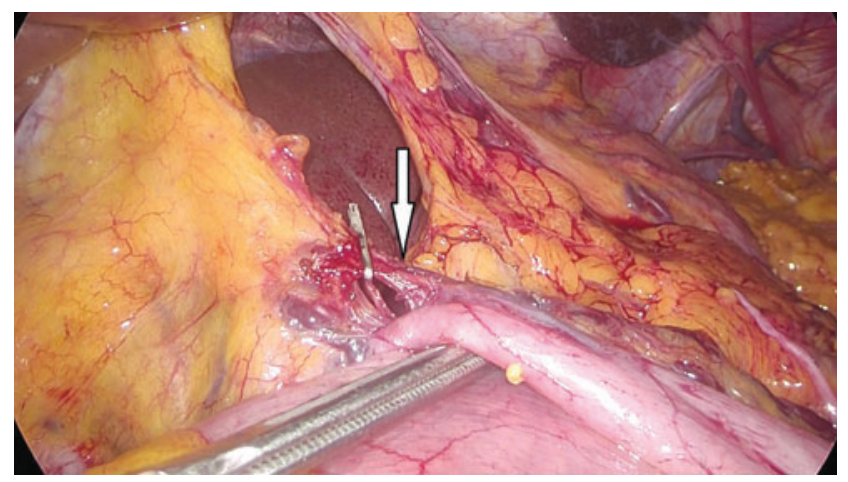

FIG. 6. Right gastric artery ligation (arrow).

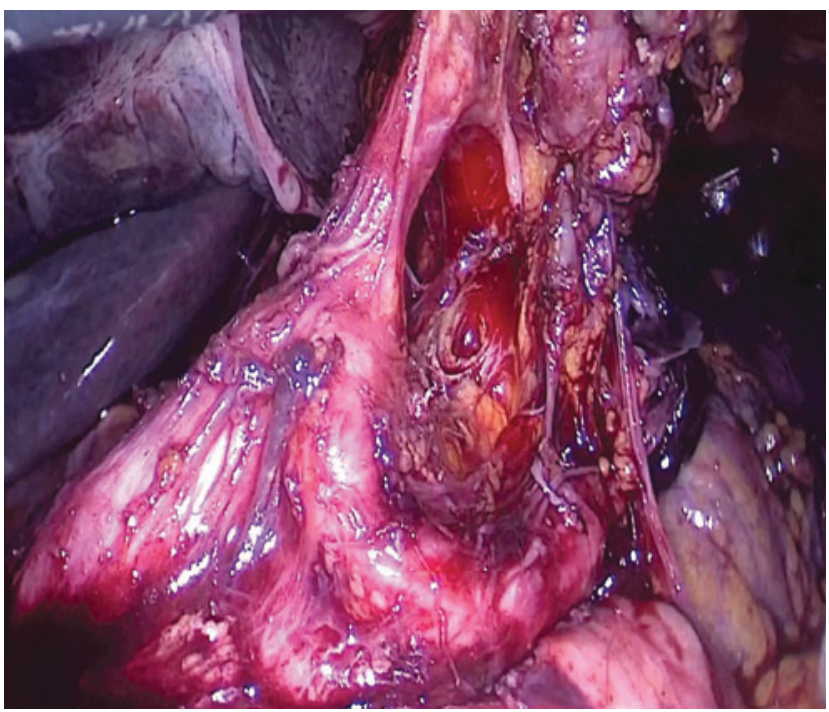

FIG. 7. Dissection of the celiac trunk.

risk factors affecting the dependent qualitative variable. Survival analyses on qualitative and quantitative variables were performed using the Kaplan-Meier method, and statistical significance between the groups was established using the log-rank test. Multivariate analyses were performed using the Cox proportional hazard model to examine the factors affecting survival. In the univariate KaplanMeier analysis, significant variables $(P<.05)$ were included in the Cox proportional hazard model. Statistical significance accepted as 0.05 .

\section{Results}

One hundred forty-six patients underwent laparoscopic gastrectomy for gastric cancer. Fifty-one (34.9\%) of the patients were female; $95(65.1 \%)$ were male. The mean \pm standard deviation and median (minimum-maximum) values of the patients were 60.92 \pm 14.13 and 64.00 (22.00-93.00), respectively (Table 1$)$. Eighty-seven $(59.6 \%)$ cases were located in

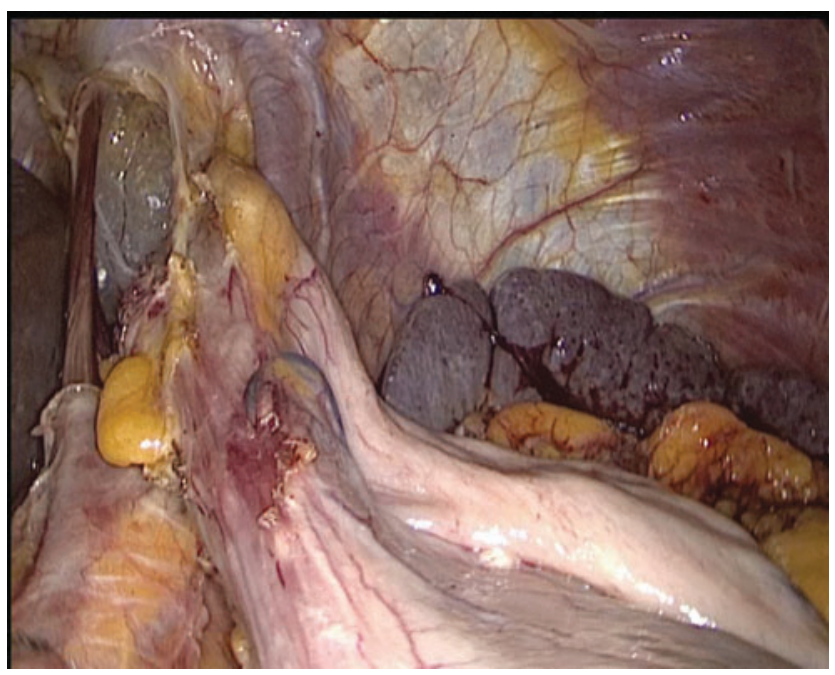

FIG. 8. Dissection of the paracardiac region. 


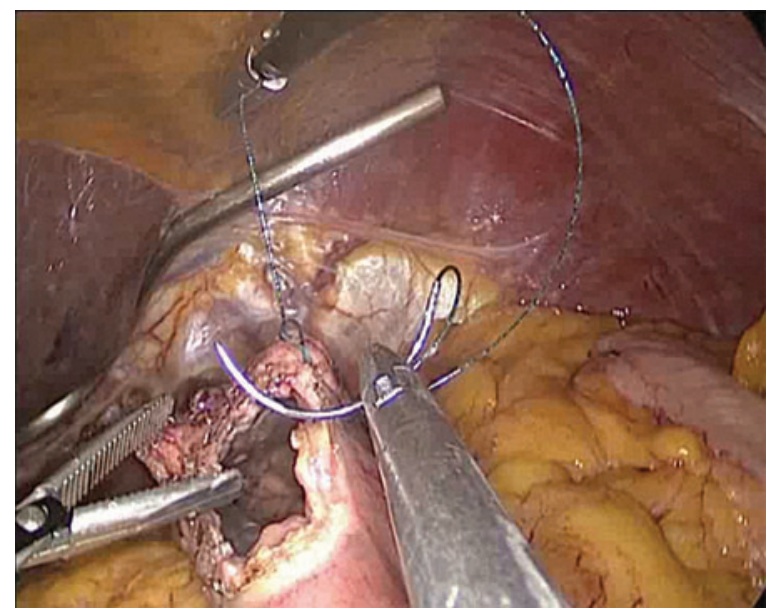

FIG. 9. Suturing the stomach wall with a barbed stitch laparoscopically.

the antrum, $29(19.9 \%)$ were in the cardia region and 30 $(20.5 \%)$ were in the corpus region. There was no statistical significance between tumor localization and survival. Overall, $106(72.6 \%)$ of 146 patients were alive, while 40 $(27.4 \%)$ were ex. The mean survival was 21.8 months $(0$ 69). Postoperative mortality was seen in 9 patients $(6.2 \%)$ and our disease-free survival rate was $70.5 \%$. Recurrence occurred in $14(9.6 \%)$ of all patients. Oral enteral nutrition was started on a mean 3.32 days. $^{1-15}$ The length of hospital stay was 8.8 days, and if postoperative mortality was excluded, it ranged from 4 to 50 days.

Univariate logistic regression analyses are shown in Table 2. The ratio of the number of metastatic lymph nodes and the number of metastatic lymph nodes to the total number of lymph nodes was found to be significantly associated with poor survival $(P<.05)$. Also, when the number of metastatic lymph nodes was increased by 1 unit, the negative effect on survival was 1.084 , whereas the ratio of the metastatic lymph node to total lymph node by 1 unit had a 7.842-fold negative effect on survival.

Table 3 shows the univariate Kaplan-Meier analysis results and the 1-, 3-, and 5-year survival probabilities of the

\section{Table 2. Univariate Logistic Regression FOR MORTALITY}

\begin{tabular}{|c|c|c|c|c|c|c|}
\hline \multirow[b]{2}{*}{$\begin{array}{l}\text { Variables } \\
\text { (references) }\end{array}$} & \multirow[b]{2}{*}{$\beta$} & \multirow[b]{2}{*}{$S E$} & \multirow[b]{2}{*}{$\mathrm{P}$} & \multirow[b]{2}{*}{$O R$} & \multicolumn{2}{|c|}{$\begin{array}{c}95 \% \text { Confidence } \\
\text { interval }\end{array}$} \\
\hline & & & & & $\begin{array}{l}\text { Lower } \\
\text { limit }\end{array}$ & $\begin{array}{l}\text { Upper } \\
\text { limit }\end{array}$ \\
\hline $\begin{array}{l}\text { Met lymph } \\
\text { count }\end{array}$ & 0.081 & 0.038 & .034 & 1.084 & 1.006 & 1.168 \\
\hline $\begin{array}{l}\text { Total lymph } \\
\text { count }\end{array}$ & -0.011 & 0.021 & .596 & 0.989 & 0.949 & 1.031 \\
\hline Met/total & 2.059 & 0.915 & .024 & 7.842 & 1.306 & 47.093 \\
\hline CA19-9 & -0.347 & 0.287 & .227 & 0.707 & 0.402 & 1.241 \\
\hline $\begin{array}{l}\text { CEA met } \\
\text { lymph }\end{array}$ & 0.002 & 0.004 & .571 & 1.002 & 0.994 & 1.011 \\
\hline
\end{tabular}

Bold indicates statistically significant.

CEA, carcinoembryonic antigen; OR, odds ratio; SE, standard error. variables affecting survival. The mean \pm standard error, median \pm SD values, and $P$ values that test their statistical significance for these periods are indicated.

Normal red cell distribution width (RDW) value of the patients was accepted as $11.5 \%-14.5 \%$, and there were 48 patients $(32.8 \%)$ with $14.5 \%$ or more. There was statistical significance between RDW height and prognosis $(P<.001)$. Albumin values of $3.5 \mathrm{~g} / \mathrm{dL}$ and above were accepted normal and below $3.5 \mathrm{~g} / \mathrm{dL}$ were accepted hypoalbuminemia. The number of patients with hypoalbuminemia was 33 (22.6\%). Survival was poor in patients with hypoalbuminemia $(P<.001)$. Among the tumor markers in the preoperative period, CA19-9 was found high in $22(15.06 \%)$ patients and carcinoembryonic antigen (CEA) in $23(15.75 \%)$ patients. While CA19-9 was statistically significant $(P=.001)$, CEA had no statistically significant $(P=.143)$ relationship with prognosis. Tumor markers and metastatic lymph node ratio effect on survival was not statistically significant $(P>.05)$.

LASG was performed in 103 patients $(70.5 \%)$, LATG and D2 dissections in 43 patients $(29.5 \%)$. In patients with LATG, anastomosis leakage was higher than those with LASG, and a statistically significant difference was found between these two groups $(P=.013)$. In patients who underwent LATG, hospitalization stay and oral enteral initiation were longer, and a statistically significant difference was found between the two groups $(P=.003$ and $P=.001)$. There was no statistical significant in terms of overall survival, disease-free survival, and deficit conversion $(P>.05)$.

Anastomoses were performed by intracorporeal or minilaparotomy. After mini-laparotomy was performed in 86 $(58.9 \%)$ of the patients, $54(37 \%)$ were performed intracorporeal anastomosis. The anastomosis of 6 patients who were converted from laparoscopy was also performed after the open conversion. Roux-en-Y anastomosis was performed in all patients. Longer survival was observed in patients who underwent anastomosis after mini-laparotomy, and it was found statistically significant $(P=.038)$.

Six of the patients $(6.1 \%)$ had an open conversion. Open conversion causes were peri-organ invasion (colon and pancreas) in 2 , bulky lymph nodes in 1 , left replaceable hepatic artery injury in 1 , and esophagus mobilization in 2 patients. These patients had worse prognosis $(P=.02)$.

Postoperative complications occurred in 18 patients. While 2 of the 3 patients with duodenal stump leak improved with medical treatment, the other patient was operated again. Pleural effusion occurred in 1 patient and catheter was inserted into the pleural cavity and drainage was achieved. Colon resection was performed in 1 patient who developed transverse colon ischemia. Anastomotic stenosis and proximal surgical margin positivity developed in 1 patient, and both had complementary total gastrectomy. In 2 of the patients, the intraabdominal abscess was developed and the catheter was inserted into the abdominal cavity by interventional radiology. When postoperative bleeding occurred in 2 patients, 1 patient was operated again while the other was followed. Anastomosis leakage occurred in 7 patients. One of the leaks was enteroenterostomy, 5 were esophagojejunostomy, and 1 was gastroenterostomy anastomosis. While most patients with anastomosis leakage were undergoing revision surgery, 2 improved with medical treatment, 1 from esophagojejunostomy and the other from gastroenterostomy. There was no statistically significant relationship between 
Table 3. Kaplan-Meier Analysis Results

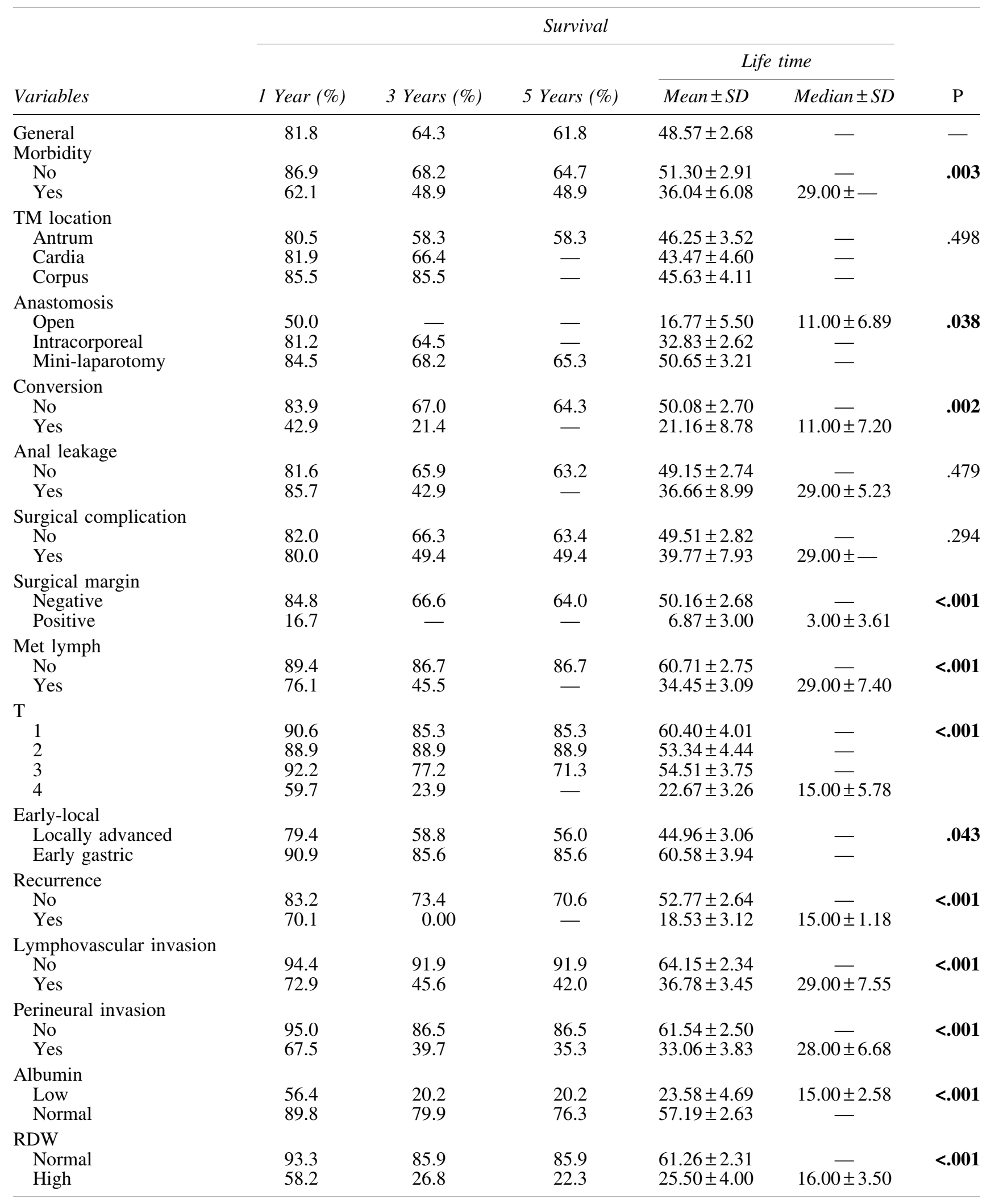

Bold indicates statistically significant.

RDW, red cell distribution width; SD, standard deviation; TM, tumor. 
anastomosis leak and prognosis $(P>.05)$. There was no statistically significant difference found between prognosis and all surgical complications $(P>.05)$. Seven patients were reoperated due to complications, and their prognosis was worse $(P=.05)$.

We classified the patients according to the Clavien-Dindo classification system in terms of postoperative morbidity. While there were 100 patients in group 1, there were 22 in group 2, 8 in group 3a, 7 in group $3 b, 1$ in group 4, and 8 in group 5. Likewise, we divided the patients into two groups as medium (Clavien-Dindo 1-2) and severe (Clavien-Dindo $3 a-3 b-4)$. While 122 patients were in the middle group, 16 patients were in the heavy group. As a result of the statistical analysis conducted, the survival significantly decreases as you move from the middle group to the heavy group or move from group 1 to other groups (morbidity increases) $(P=.003)$.

According to the pathology reports, 84 (57.5\%) of the patients had lymphovascular invasion (LVI) and $64(43.8 \%)$ had perineural invasion (PNI). The presence of LVI and PNI showed poor survival $(P<.001)$. The surgical margin was positive in 6 patients, and the proximal and distal surgical margins were positive in 3 patients. Only one of these patients was reoperated; others were directed to medical oncology after discussion at the council due to age, additional comorbidities, and postoperative complications. A statistically significant difference was found between the surgical margin positivity and prognosis $(P<.001)$. The average number of metastatic lymph nodes was $8.41(0-40)$ and the average number of total lymph nodes was 23.08 (4-52). Mortality was higher in patients with metastatic lymph nodes $(P<.001)$. When classified according to $\mathrm{T}$ stage, 32 patients were $\mathrm{T}_{1}(21.9 \%), 18$ patients were $\mathrm{T}_{2}(12.3 \%), 55$ patients were $\mathrm{T}_{3}(37.7 \%)$, and 41 patients were $\mathrm{T}_{4}(28.1 \%)$. It was observed that survival decreased as the $\mathrm{T}$ stage increased $(P<.001)$. The proportions of patients with $\mathrm{T}_{2}$ and $\mathrm{T}_{3}$ stages were very close. $\mathrm{N}$ was positive in $78(53.4 \%)$ of patients and $\mathrm{N}$ was negative in $68(46.6 \%)$. Mortality was found to be high in patients with $\mathrm{N}$-positive results and was statistically significant $(P<.05)$. When $\mathrm{T}_{2} \mathrm{~N}_{0}$ and $\mathrm{T}_{2} \mathrm{~N}+$ patients were compared, no statistical difference was found between the two groups $(P>.05)$. When $\mathrm{T}_{3} \mathrm{~N}_{0}$ and $\mathrm{T}_{3} \mathrm{~N}+$ patients were compared, no statistical difference was found between the two groups $(P>.05)$.

We divided our patients into two groups as early and local advanced gastric cancer. We defined early gastric cancer as $\mathrm{T}_{1} \mathrm{~N}_{\mathrm{x}} \mathrm{M}_{\mathrm{x}}$ and all other patients as locally advanced gastric cancer. Thirty-three $(22.6 \%)$ of the patients were with early gastric cancer, and $113(77.4 \%)$ were with locally advanced gastric cancer. There was a statistically significant difference in survival between the two groups and was lower in locally advanced gastric cancers $(P=.026)$. There was no statistically significant difference between the two groups in terms of anastomosis leakage, postoperative mortality, anastomosis technique, and oral feeding, but postoperative mortality was also $P=.055 ; 88 \%$ of cases were with locally advanced gastric cancer and $12 \%$ of cases with early gastric cancer. Although not statistically significant, it was found significantly higher in locally advanced cancers. In general, survival was found to be higher in early gastric cancers and it was statistically significant $(P=.043)$. Sixteen $(11 \%)$ of the patients received neoadjuvant therapy. As neoadjuvant therapy, FOLFOX (Folinic acid+Fluorouracil+Oxaliplatin), FLOT (Folinic acid+Fluorouracil+Oxaliplatin+Taxane), DCF (Docetaxel+Fluorouracil+Cisplatin), Carboplatin, and Paclitaxel treatment regimens were performed. It was statistically found that survival was worse in patients receiving neoadjuvant therapy $(P=.046)$. At least one blood product (erythrocyte, fresh frozen plasma, and platelet) was used in $33(22.6 \%)$ of the patients and it was found that it had a negative effect on total survival $(P<.001)$.

In these 5 years, we divided the cases into two groups as the first 3 and the last 2 years. Twenty (29\%) of $69(46.2 \%)$ patients operated in the first 3 years and $20(26 \%)$ of 77 $(53.8 \%)$ patients operated in the last 2 years were exes. There was no statistically significant difference between the two groups in terms of overall mortality, postoperative mortality, and anastomosis leakage $(P>.05)$, while survival was statistically better in the first 3 years $(P<.05)$.

Table 4. Cox Regression Analysis

\begin{tabular}{|c|c|c|c|c|}
\hline \multirow[b]{3}{*}{ Variables } & \multicolumn{4}{|c|}{ Survival } \\
\hline & \multirow[b]{2}{*}{ Hazard ratio } & \multicolumn{2}{|c|}{ 95\% Confidential interval } & \multirow[b]{2}{*}{$\mathrm{P}$} \\
\hline & & Lower limit & Upper limit & \\
\hline \multicolumn{5}{|l|}{ Conversion } \\
\hline No & 1 (reference) & - & - & - \\
\hline Yes & 3.270 & 1.257 & 8.505 & .015 \\
\hline \multicolumn{5}{|c|}{ Lymphovascular invasion } \\
\hline No & 1 (reference) & & & - \\
\hline Yes & 5.280 & 1.803 & 15.457 & .002 \\
\hline \multicolumn{5}{|l|}{ RDW } \\
\hline Normal & 1 (reference) & - & - & - \\
\hline Elevated & 3.511 & 1.628 & 7.571 & .001 \\
\hline \multicolumn{5}{|l|}{ Albumin } \\
\hline Normal & 1 (reference) & & & - \\
\hline Low & 4.146 & 2.096 & 8.202 & $<.001$ \\
\hline
\end{tabular}

RDW, red cell distribution width. 
In the multivariate analysis according to the Cox regression analysis, open conversion, LVI, PNI, and hypoalbuminemia were found statistically significant in terms of prognosis $(P<.001)$. The morbidity, anastomosis, open conversion, surgical margin, met lymph, T, early local, recurrence, LVI, PNI, albumin, and RDW variables that were significant as a result of the Kaplan-Meier analysis in Table 3 were included in the Cox regression analysis.

Considering all the descriptive variables in the study together, the results of the model were obtained when Cox regression analysis was performed with the backward selection method to evaluate which factors affect survival. As can be seen in Table 4, open conversion, LVI, RDW, and Albumin variables remained in the model $(P<.005)$. Patients with open conversion are 3.27 times more at risk than those without open conversion; those with LVI are 5.28 times more at risk than those without, those with RDW elevated are 3.55 times more at risk than those without, and patients with hypoalbuminemia are 4 times more at risk than those without.

\section{Discussion}

Gastrectomy and lymphadenectomy must be done for curative resection in gastric cancer. ${ }^{11}$ Many studies have been published recently stating that laparoscopic surgery is superior to open surgery. ${ }^{12,13}$ Laparoscopic gastrectomy is becoming more and more common and the reasons are shortterm similar oncological results, faster return to normal postoperatively, early gained bowel functions, less pain, and less wound infection development. ${ }^{14,15}$ The fact that reconstruction requires experience and difficulty of lymphadenectomy are the factors that make laparoscopy difficult. As the experience increases, reconstruction and lymphadenectomy will be performed safer. Depending on these, use of laparoscopy in gastric cancer surgery will become common.

In the literature, postoperative morbidity is around 4\%$27 \%{ }^{16}$ in cases with open gastrectomy, and on average, it is around $8 \%-24 \%$ in cases with laparoscopic gastrectomy. ${ }^{17-20}$ In the literature, morbidity of open and laparoscopic gastrectomy was compared and similar rates were found. ${ }^{21}$ The mortality rate after open surgery in the literature is $0 \%-$ $6.6 \% .^{22,23}$ In our study, the postoperative morbidity rate was $19.9 \%$ and the mortality rate was $6.2 \%$. Kitano et al. showed that the rates of morbidity and mortality in early gastric cancers were $14.8 \%-0 \%$, respectively, ${ }^{24}$ Fujiwara et al. reported $22.3 \%-0 \%$, respectively. ${ }^{25}$ In our series, the morbidity and mortality rate in early gastric cancer was found $18.18 \%$ to $3.03 \%$, respectively. In our study, the postoperative complication rate was found as $10.3 \%$. Morbidity and mortality do not increase in experienced centers for laparoscopic surgery, moreover, morbidity and mortality are lower in these centers. All these show us that laparoscopic gastrectomy does not increase morbidity and mortality.

Anastomosis leaks cause major morbidity and mortality after gastrectomy. In the literature, the rate of anastomosis leakage after laparoscopic surgery is around $1.1 \%-2.7 \% .{ }^{26} \mathrm{In}$ our study, the rate of anastomosis leakage was $4.8 \%$, as close to the literature. The reason why it was more than reported in the literature is that the locally advanced gastric cancer was higher. In early gastric cancer patients, anastomosis leakage was $0 \%$, in the same with the literature. In our study, anastomosis leaks were slightly higher after LATG and that was not statistically significant $(P>.05)$. The reason for this may be that conventional esophagojejunostomy was a difficult anastomosis performed in a narrow area. There was no statistically significant relationship between anastomosis leak and prognosis $(P>.05)$. This indicates that anastomosis leaks can be detected early and can be overcome with an appropriate treatment approach, and as a consequence of these, the prognosis remains unaffected. Lee et al. reported less bleeding in the anastomosis area in LATG. ${ }^{27}$ No bleeding from the anastomosis area was observed in any of the patients included in our study. This shows that better exploration will be achieved by laparoscopy in a narrow anastomosis region and more rigorous hemostasis can be achieved in laparoscopy. In some studies in the literature, it has been reported that pancreatic fistula rates are high, especially after conventional surgery ${ }^{28}$ There were no pancreatic fistula cases in our study. The reason for the less pancreatic fistula in laparoscopic surgery may be to perform lymph node dissection at a larger magnification than open surgery.

Studies have shown that the length of hospital stay after laparoscopic surgery is shorter in laparoscopic surgery and postoperative complications are similar to those of open surgery. ${ }^{29,30}$ In our study, the hospital stay is on average 8.8 days and there is no increase in complications. Lee et al. compared laparoscopic distal/total gastrectomy and showed that the duration of hospitalization was slightly longer in total gastrectomy. ${ }^{31}$

In our study, it was observed that the patients who had LATG had a longer hospital stay. We believe that LATG can be done safely in experienced centers by following oncological principles without increasing complication rates although it takes a little longer.

In the literature, the 5-year survival rate in patients undergoing laparoscopic gastrectomy is around $95 \% .^{21,32,33} \mathrm{In}$ our study, this rate was $72.6 \%$. The reason why this rate was less than the literature, early-stage gastric cancers were included in the other study, and in our study, advanced stage gastric cancers were in the majority and patients who were performed at the end of the learning curve had a short followup period. In a study of Bo et al., ${ }^{34}$ the 5 -year survival rate in advanced gastric cancers was $49 \%$, while in our study, survival was $68.1 \%$ in local advanced cancers and $87.87 \%$ in early gastric cancers. This shows that the oncological results of laparoscopic surgery are successful.

In 18 patients with stage $\mathrm{T}_{2}$, survival was $88.9 \%$, and survival in 55 patients with $\mathrm{T}_{3}$ was $81.8 \%$. These results show us that laparoscopic surgery can be performed safely and effectively in $\mathrm{T}_{2}-\mathrm{T}_{3}$ tumors. As the $\mathrm{T}$ stage increases, metastatic lymph nodes increase and survival decreases. Survival rates were $\mathrm{T}_{3} \mathrm{~N}_{0} 88.9 \%$ and $\mathrm{T} 3 \mathrm{~N}+78.4 \% ; \mathrm{T}_{2} \mathrm{~N}_{0}$ is $86.7 \%$ and $\mathrm{T}_{2} \mathrm{~N}+100 \%$. Today, although there are doubts about the laparoscopic surgical approach in locally advanced gastric cancer, these results show us that laparoscopy can be performed safely in the locally advanced stages as in the early stage, and it is necessary to minimize the doubts with future studies. Lee et al. have reported that laparoscopic surgery was difficult in $\mathrm{T}_{3}$ tumors, tumor seeding and port-site recurrence could develop. ${ }^{35}$ We disagree with this. We think that the use of a protective bag when removing the specimen, minimal touch to the tumor, reducing carbon dioxide leakages from the trocars, removing trocars after emptying all the intraabdominal gas, and closing the fascia at the port sites will 
prevent tumor seeding and port-site recurrence. Port recurrence has not been observed in our cases up to now.

Recurrence in gastric cancers occurs especially in the liver and peritoneal region. The standard treatment of relapse is not clearly defined. In some studies, the contribution of complementary gastrectomy to survival has been shown. ${ }^{36,37}$ In our study, the recurrence rate was $9.6 \%$. The recurrence rate in gastric cancers with gastrectomy and D2 dissection is between $1.4 \%$ and $6.4 \%$ in the literature. ${ }^{38-40}$ In our study, the recurrence rate for early gastric cancers was $0 \%$. In locally advanced gastric cancer, it was $12.38 \%$. These results show that laparoscopic surgery does not increase recurrence in gastric cancer and can be safely performed as long as oncological rules are followed.

It is a known fact that the curative results of laparoscopic surgery in early gastric cancers are similar to open surgery. The real question is laparoscopic surgery effectiveness in advanced gastric cancers. In our study, we compared early gastric cancer and advanced gastric cancers in some factors such as postoperative complications, hospitalization, curative resection, and enteral onset, there was no statistical significant difference $(P>.05)$. This suggests that laparoscopic surgery will be performed safely in advanced-stage patients. The main suggestion was the idea that lymph node dissection cannot be performed laparoscopically, ${ }^{2}$ but nowadays, lymph node dissection can now be performed at the same rate as open surgery with a minimally invasive approach. Thus, laparoscopic surgery does not have the disadvantage to achieve curative results.

In a study, the number of lymph nodes dissected was stated to be $30 \pm 10 .^{41}$ In a similar study, it was stated as $29 \pm 11 .^{42}$ In our study, an average of $23.08 \pm 8.9$ (4-52) lymph nodes were dissected. Lymph node dissection (D2) has been proved to provide a survival improvement in gastriccancer. ${ }^{43}$ The important point here is to dissect a sufficient number of lymph nodes. This allows us to predict optimal staging and patient survival. ${ }^{44}$ In our study, adequate lymph node dissection was performed laparoscopically.

Enteral onset time in the literature is postoperative 3-8 days. $^{45}$ In our study, the average onset of enteral feeding is 3.32 days. We think that there is no difference in laparoscopic or open surgery in enteral onset. In previous studies, it was stated that the duration of hospitalization after laparoscopic gastrectomy was shorter with an average of 7-19 days compared to the open surgery. ${ }^{46,47}$ In our study, the mean duration of hospitalization was 8.87 days, while it was 10.5 days in total gastrectomies and 8.1 days in subtotal gastrectomies, and a statistically significant difference was found between the two groups $(P=.003)$. The average conversion rate is $6.1 \%$ in our study. While early gastric cancer cases were $3.03 \%$, it was $5.3 \%$ in advanced cases. The open conversion rates in the literature range from $2.3 \%$ to $25 \% .{ }^{48,49}$ As the experience in laparoscopic surgery increases and technology improves, conversion rates decrease significantly.

Studies are indicating that the operation time is between 144 and 348 minutes. ${ }^{50}$ Our average operation time was 142.69 (80-300) minutes. When laparoscopic surgery was just started, the time was expected to be longer. However, as the number of cases increases and standardization is achieved, the duration decreases. In the literature, it has been shown that the time is shorter after the learning curve ends. ${ }^{51}$ In total gastrectomy cases, the duration of surgery was longer than the subtotal ones. We believe that longer operations do not increase complications and minimally invasive surgery should not be abandoned. In our study, high RDW value (14.5\% and higher were accepted) was bad prognostic as one of the factors affecting survival or as an indicator $(P<.001)$. It is already known that RDW increases in inflammation and affects prognosis. Likewise, low albumin value and CA19-9 elevation were found to be poor prognostic factors $(P<.001$ and $P=0.001)$. Nutritional markers are important for prognosis and postoperative complications, and albumin is used as a nutritional marker in the clinical practice. This shows that we should provide preoperative nutritional support to patients with hypoalbuminemia. In this way, we can reduce the negative effects on prognosis and postoperative morbidity. In our study, the duration from the diagnosis of cancer to the operation was 23.26 days (1-330) and the length of time was extended due to the additional neoadjuvant treatments. In patients without neoadjuvant therapy, the average time from diagnosis to operation was 10.73 days. We think that this time is sufficient. Preoperative blood product was used in 33 patients. These cases were found to have worse survival $(P<.001)$. We think that this situation is caused by the immunosuppressive effect of the blood product.

Whether the anastomosis form is intracorporeal or extracorporeal is a matter of preference and does not affect oncological results. In our clinic, an increasing number of intracorporeal anastomoses are performed, and we think that intracorporeal anastomosis is safer. The difficulties of extracorporeal anastomosis are enlargement of the incision due to insufficient mini-laparotomy, intestinal injuries due to difficulty in exploration, postoperative pain especially in obese patients due to the tension applied to the retractor, and late bowel movement. Clear vision can be provided and intestinal injuries are less during laparoscopic anastomosis. The factor that forces us during anastomosis is the surgical margin status, especially in nonpalpable tumors. For this reason, we performed preoperative endoscopy in most cases. After resection, the specimen was examined and the surgical margin was evaluated. In undergoing total gastrectomy patients, we sent the surgical margin to frozen section. Some methods have been developed in the literature to find tumor placement, and preoperative clipping, preoperative ultrasonography, ${ }^{52}$ or preoperative endoscopic staining ${ }^{53}$ are performed. We do not use these methods in our clinic. In the intracorporeal anastomosis technique, we mostly use staplers. We rarely close it manually. In anastomosis made with staplers, we manually close the open space. We do not prefer to use the stapler tool when closing this gap, because we think that otherwise there will be more anastomosis stenosis.

A Korean study stated that the learning curve was 50 cases. ${ }^{54}$ In our clinic, we believe that the learning curve has fewer cases. We think that surgeons who are performing standard laparoscopic surgery (cholecystectomy, hernia repair, and colectomy) can reduce this curve to 20 cases. To achieve this, the surgical procedure should be performed within standardization and accompanied by a senior surgeon. When we differentiate our patients as those operated for the first 3 and last 2 years, the first 3 years' survival was better $(P<.05)$. We associated this with the fact that the first 3 years' cases have a longer follow-up period, while in the last 2 years, more patients were operated and the stage was more advanced. 
The limitations of our study are the following: it is not randomized, and it is a retrospective and single-center study. Besides, some of the patients have not completed the 5-year follow-up period yet.

In conclusion, although laparoscopic gastrectomy is a reliable and feasible method for gastric cancer, the standardization of laparoscopic surgery is required in clinics. After gaining sufficient experience, curative resection results are achieved with the same or even better oncological results as open surgery. Therefore, laparoscopic gastrectomy is the gold standard in gastric cancer surgery.

\section{Acknowledgment}

We thank all members of the Turkish Surgical Oncology Association who supported the writing of this article.

\section{Disclosure Statement}

No competing financial interests exist.

\section{Funding Information}

No funding was received for this article.

\section{References}

1. Torre LA, Bray F, Siegel RL, Ferlay J, Lortet-Tieulent J, Jemal A. Global cancer statistics, 2012. CA Cancer J Clin 2015;65:87-108.

2. Kitano S, Iso Y, Moriyama M, Sugimachi K. Laparoscopyassisted Billroth I gastrectomy. Surg Laparosc Endosc 1994;4:146-148.

3. Ohtani H, Tamamori Y, Noguchi K, Azuma T, Fujimoto S, Oba $\mathrm{H}$, et al. A meta-analysis of randomized controlled trials that compared laparoscopy-assisted and open distal gastrectomy for early gastric cancer. J Gastrointest Surg 2010;14:958-964.

4. Kim Y-W, Yoon HM, Yun YH, Nam BH, Eom BW, Baik $\mathrm{YH}$, et al. Long-term outcomes of laparoscopy-assisted distal gastrectomy for early gastric cancer: Result of a randomized controlled trial (COACT 0301). Surg Endosc 2013;27:4267-4276.

5. Chen K, Pan Y, Zhai S-T, Yu W-h, Pan J-h, Zhu Y-p, et al. Totally laparoscopic versus open total gastrectomy for gastric cancer: A case-matched study about short-term outcomes. Medicine 2017;96:e8061.

6. Lee J, Nam BH, Ryu K, Ryu S, Park Y, Kim S, et al. Comparison of outcomes after laparoscopy-assisted and open total gastrectomy for early gastric cancer. Br J Surg 2015;102:1500-1505.

7. Adachi Y, Shiraishi N, Shiromizu A, Bandoh T, Aramaki M, Kitano S. Laparoscopy-assisted Billroth I gastrectomy compared with conventional open gastrectomy. Arch Surg 2000;135:806-810.

8. Wang W, Li Z, Tang J, Wang M, Wang B, Xu Z. Laparoscopic versus open total gastrectomy with $\mathrm{D} 2$ dissection for gastric cancer: A meta-analysis. J Cancer Res Clin Oncol 2013;139:1721-1734.

9. Gress DM, Edge SB, Greene FL, Washington MK, Asare EA, Brierley JD, et al. Principles of cancer staging. In: Amin MB, Edge S, Greene F, Byrd DR, Brookland RK, Washington MK, et al. (eds.). AJCC Cancer Staging Manual 8th ed. New York, NY: Springer, 2017.
10. Association JGC. Japanese gastric cancer treatment guidelines 2014 (ver. 4). Gastric Cancer 2017;20:1-19.

11. Kim JP. Current status of surgical treatment of gastric cancer. J Surg Oncol 2002;79:79-80.

12. Peng J, Song H, Yang Z, Xiang J, Diao D, Liu Z. Metaanalysis of laparoscopy-assisted distal gastrectomy and conventional open distal gastrectomy for early gastric cancer. Chin J Cancer 2010;29:349-354.

13. Yamashita K, Miyazaki Y, Takahashi T, Masuike Y, Motoori M, Kimura Y, et al. Safety and feasibility of laparoscopic gastrectomy for gastric cancer patients with a history of abdominal surgery. Surg Today 2017;47: 1274-1281.

14. Katai H, Sasako M, Fukuda H, Nakamura K, Hiki N, Saka M, et al. Safety and feasibility of laparoscopy-assisted distal gastrectomy with suprapancreatic nodal dissection for clinical stage I gastric cancer: A multicenter phase II trial (JCOG 0703). Gastric Cancer 2010;13:238-244.

15. Noshiro H, Shimizu S, Nagai E, Ohuchida K, Tanaka M. Laparoscopy-assisted distal gastrectomy for early gastric cancer: Is it beneficial for patients of heavier weight? Ann Surg 2003;238:680.

16. Lee H-J, Yang H-K. Laparoscopic gastrectomy for gastric cancer. Dig Surg 2013;30:132-141.

17. Park DJ, Han S-U, Hyung WJ, Kim MC, Kim W, Ryu SY, et al. Long-term outcomes after laparoscopy-assisted gastrectomy for advanced gastric cancer: A large-scale multicenter retrospective study. Surg Endosc 2012;26:1548-1553.

18. Shinohara T, Satoh S, Kanaya S, Ishida Y, Taniguchi K, Isogaki J, et al. Laparoscopic versus open D2 gastrectomy for advanced gastric cancer: A retrospective cohort study. Surg Endosc 2013;27:286-294.

19. Hwang SI, Kim HO, Yoo $\mathrm{CH}$, Shin JH, Son BH. Laparoscopic-assisted distal gastrectomy versus open distal gastrectomy for advanced gastric cancer. Surg Endosc 2009;23:1252-1258.

20. Usui S, Yoshida T, Ito K, Hiranuma S, Kudo S-E, Iwai T. Laparoscopy-assisted total gastrectomy for early gastric cancer: Comparison with conventional open total gastrectomy. Surg Laparosc Endosc Percutan Tech 2005;15:309314.

21. Mochiki E, Toyomasu Y, Ogata K, Andoh H, Ohno T, Aihara R, et al. Laparoscopically assisted total gastrectomy with lymph node dissection for upper and middle gastric cancer. Surg Endosc 2008;22:1997-2002.

22. Jeong O, Jung MR, Kim GY, Kim HS, Ryu SY, Park YK. Comparison of short-term surgical outcomes between laparoscopic and open total gastrectomy for gastric carcinoma: Case-control study using propensity score matching method. J Am Coll Surg 2013;216:184-191.

23. Okabe H, Obama K, Tsunoda S, Tanaka E, Sakai Y. Advantage of completely laparoscopic gastrectomy with linear stapled reconstruction: A long-term follow-up study. Ann Surg 2014;259:109-116.

24. Kitano S, Shiraishi N, Uyama I, Sugihara K, Tanigawa N, Group JLSS. A multicenter study on oncologic outcome of laparoscopic gastrectomy for early cancer in Japan. Ann Surg 2007;245:68.

25. Fujiwara M, Kodera Y, Misawa K, Kinoshita M, Kinoshita $\mathrm{T}$, Miura S, et al. Longterm outcomes of early-stage gastric carcinoma patients treated with laparoscopy-assisted surgery. J Am Coll Surg 2008;206:138-143.

26. Kim W, Song KY, Lee H-J, Han SU, Hyung WJ, Cho GS. The impact of comorbidity on surgical outcomes in 
laparoscopy-assisted distal gastrectomy: A retrospective analysis of multicenter results. Ann Surg 2008;248:793799.

27. Lee S, Ahn JY, Na S, Na HK, Jung KW, Kim DH, et al. Clinical features of postoperative anastomotic bleeding after gastrectomy and efficacy of endoscopic hemostasis: A case-control study. Surg Endosc 2017;31:3210-3218.

28. Hiki N, Honda M, Etoh T, Yoshida K, Kodera Y, Kakeji Y, et al. Higher incidence of pancreatic fistula in laparoscopic gastrectomy. Real-world evidence from a nationwide prospective cohort study. Gastric Cancer 2018;21:162-170.

29. Strong VE, Devaud N, Allen PJ, Gonen M, Brennan MF, Coit D. Laparoscopic versus open subtotal gastrectomy for adenocarcinoma: A case-control study. Ann Surg Oncol 2009;16:1507-1513.

30. Haverkamp L, Weijs TJ, van der Sluis PC, van der Tweel I, Ruurda JP, van Hillegersberg R. Laparoscopic total gastrectomy versus open total gastrectomy for cancer: A systematic review and meta-analysis. Surg Endosc 2013;27: 1509-1520.

31. Lee SE, Ryu KW, Nam BH, Lee JH, Kim YW, Yu JS, et al. Technical feasibility and safety of laparoscopy-assisted total gastrectomy in gastric cancer: A comparative study with laparoscopy-assisted distal gastrectomy. J Surg Oncol 2009;100:392-395.

32. Eom BW, Kim Y-W, Lee SE, Ryu KW, Lee JH, Yoon HM, et al. Survival and surgical outcomes after laparoscopyassisted total gastrectomy for gastric cancer: Case-control study. Surg Endosc 2012;26:3273-3281.

33. Sakuramoto S, Kikuchi S, Futawatari N, Katada N, Moriya $\mathrm{H}$, Hirai $\mathrm{K}$, et al. Laparoscopy-assisted pancreas-and spleen-preserving total gastrectomy for gastric cancer as compared with open total gastrectomy. Surg Endosc 2009; 23:2416.

34. Bo T, Peiwu Y, Feng Q, Yongliang Z, Yan S, Yingxue H, et al. Laparoscopy-assisted vs. open total gastrectomy for advanced gastric cancer: Long-term outcomes and technical aspects of a case-control study. J Gastrointest Surg 2013;17:1202-1208.

35. Lee Y-J, Ha W-S, Park S-T, Choi S-K, Hong S-C. Port-site recurrence after laparoscopy-assisted gastrectomy: Report of the first case. J Laparoendosc Adv Surg Tech 2007;17: 455-457.

36. Song K-Y, Park S-M, Kim S-N, Park C-H. The role of surgery in the treatment of recurrent gastric cancer. Am J Surg 2008;196:19-22.

37. Shchepotin I, Evans S, Shabahang M, Cherny V, Buras RR, Zadorozhny A, et al. Radical treatment of locally recurrent gastric cancer. Am Surg 1995;61:371-376.

38. Ichiyoshi Y, Toda T, Minamisono Y, Nagasaki S, Yakeishi Y, Sugimachi K. Original communications recurrence in early gastric cancer. Br J Surg 1990;77:684-690.

39. Shiozawa N, Kodama M, Chida T, Arakawa A, Tur G, Koyama K. Recurrent death among early gastric cancer patients: 20-years' experience. Hepatogastroenterology 1994;41:244-247.

40. Sano T, Kobori O, Muto T. Lymph node metastasis from early gastric cancer: Endoscopic resection of tumour. Br J Surg 1992;79:241-244.

41. Hao Y, Yu P, Qian F, Zhao Y, Shi Y, Tang B, et al. Comparison of laparoscopy-assisted and open radical gastrectomy for advanced gastric cancer: A retrospective study in a single minimally invasive surgery center. Medicine 2016;95.
42. Chen Q-Y, Huang C-M, Lin J-X, Zheng C-H, Li P, Xie $\mathrm{J}-\mathrm{W}$, et al. Laparoscopy-assisted versus open D2 radical gastrectomy for advanced gastric cancer without serosal invasion: A case control study. World J Surg Oncol 2012; 10:248.

43. Wu C-W, Hsiung CA, Lo S-S, Hsieh M-C, Chen J-H, Li AF-Y, et al. Nodal dissection for patients with gastric cancer: A randomised controlled trial. Lancet Oncol 2006; 7:309-315.

44. Son T, Hyung WJ, Lee JH, Kim YM, Kim HI, An JY, et al. Clinical implication of an insufficient number of examined lymph nodes after curative resection for gastric cancer. Cancer 2012;118:4687-4693.

45. Ye L-y, Liu D-r, Li C, Li X-w, Huang L-n, Ye S, et al. Systematic review of laparoscopy-assisted versus open gastrectomy for advanced gastric cancer. J Zhejiang Univ Sci B 2013;14:468-478.

46. Haverkamp L, Ruurda J, Offerhaus G, Weijs T, Van Der Sluis P, Van Hillegersberg R. Laparoscopic gastrectomy in Western European patients with advanced gastric cancer. Eur J Surg Oncol (EJSO) 2016;42:110-115.

47. Honda M, Kumamaru H, Etoh T, Miyata H, Yamashita Y, Yoshida K, et al. Surgical risk and benefits of laparoscopic surgery for elderly patients with gastric cancer: A multicenter prospective cohort study. Gastric Cancer 2019;22: 845-852.

48. Fujiwara M, Kodera Y, Kasai Y, Kanyama Y, Hibi K, Ito $\mathrm{K}$, et al. Laparoscopy-assisted distal gastrectomy with systemic lymph node dissection for early gastric carcinoma: A review of 43 cases. J Am Coll Surg 2003;196:75-81.

49. Shimizu S, Noshiro H, Nagai E, Uchiyama A, Tanaka M. Laparoscopic gastric surgery in a Japanese institution: Analysis of the initial 100 procedures. J Am Coll Surg 2003;197:372-378.

50. Tanimura S, Higashino M, Fukunaga Y, Takemura M, Tanaka Y, Fujiwara Y, et al. Laparoscopic gastrectomy for gastric cancer: Experience with more than 600 cases. Surg Endosc 2008;22:1161-1164.

51. Schlachta CM, Mamazza J, Seshadri PA, Cadeddu M, Gregoire R, Poulin EC. Defining a learning curve for laparoscopic colorectal resections. Dis Colon Rectum 2001; 44:217-222.

52. Hyung WJ, Lim J, Cheong J, Kim J, Choi S, Song S, et al. Intraoperative tumor localization using laparoscopic ultrasonography in laparoscopic-assisted gastrectomy. Surg Endosc 2005;19:1353-1357.

53. Tanimura S, Higashino M, Fukunaga Y, Osugi H. Laparoscopic distal gastrectomy with regional lymph node dissection for gastric cancer. Surg Endos 2003;17:758-762.

54. Kim M-C, Jung G-J, Kim H-H. Learning curve of laparoscopy-assisted distal gastrectomy with systemic lymphadenectomy for early gastric cancer. World J Gastroenterol 2005;11:7508.

Address correspondence to: Ogün Erşen, $M D$ General Surgery Department Surgical Oncology Clinic Ankara University Medicine Faculty Cebeci, 06590 Çankaya/Ankara Turkey

E-mail: ogunersen@hotmail.com 